\title{
Antibiotic susceptibilty of bacteria from the Bacillus subtilis group
}

\author{
A.N. Irkitova *, A.V. Grebenshchikova, D.E Dudnik \\ Altai State University, pr. Lenina 61, Barnaul, 656049, Russia. \\ Corresponding author E-mail: Elen171987@mail.ru \\ Received 12.09.2019. Accepted: 20.10.2019
}

The ability of bacteria to quickly acquire antibiotic resistance and transfer it among different groups are created a global problem, since antibiotics are used not only in medicine, but also in agriculture. That is why to study of the antibiotic sensitivity of not only pathogenic bacteria, but also of beneficial microbes like Bacillus spp. is extremely important. Our results demonstrated that all the studied strains of the $B$. subtilis group were highly sensitive to cephalexin and enrofloxacin, while resistant to oxacillin. The $B$. subtilis $\mathrm{B}-5449$ strain was the least resistant to the studied antibiotics, and the $B$. subtilis $\mathrm{B}-2896$ strain was the most resistant.

Key words: Bacillus subtilis; Bacillus pumilus, antibiotic sensitivity; antibiotics.

\section{Introduction}

Antibiotic resistance is the resistance of bacteria to the action of natural antibiotic compounds and their derivatives. The ability of bacteria to quickly acquire antibiotic resistance and transfer it among different groups are created a global problem, since antibiotics are used not only in medicine, but also in agriculture (Sidorenko \& Tishkov, 2004).

The resistance of microorganisms to antibiotics is determined by various mechanisms:

1. The ability to produce enzymes that inactivate antibiotic compounds. These enzymes include $\beta$-lactamases, which destroy $\beta$ lactam antibiotics (penicillins, cephalosporins, carbapenems, and monolactams) and many aminoglycoside-modifying enzymes (Bush, 2009; Nikaido, 2009; Semenov et al., 2013; Petrova \& Zamyatin, 2018).

2. Active release of antibiotic out of cell (efflux). The efflux mechanism provides resistance to fluoroquinolones (synthetic compounds that have no natural analogues) and tetracyclines (Li \& Nikaido, 2009; Martinez et al., 2009).

3. Horizontal gene transfer. This mechanism allows microorganisms to quickly acquire resistance under selective antibiotic action (Alonso et al., 2001; Vinogradova et al., 2013).

4. The occurrence of mutations, leading to the formation of a phenotype of bacterial resistance. There is a change in the structure of bacterial targets of the antibiotic compounds action. Genome modifications are one of the main methods for the emergence of resistance to chemotherapy drugs (Martinez \& Baquero, 2000; Sidorenko \& Tishkov, 2004).

All these mechanisms arose long before the "era of antibiotics" and performed various physiological functions. However, human use of antibiotics has led to the selection of bacteria with the highest resistance (Vinogradova et al., 2013).

The active use of antibiotics in various industries leads to the spread of resistance among different groups of microorganisms. This creates the need for a detailed study of sensitivity to the action of antibiotics. The need to study of the antibiotic sensitivity of not only pathogenic bacteria, but also beneficial microbes, which are used as the basis for biological preparations (probiotics, agricultural biopreparations, are arisen. These bacteria include representatives of the genus Bacillus, in particular, representatives of the $B$. subtilis group, which possess a wide range of useful properties and are successfully used in various sectors of the national economy.

\section{Materials and methods}

\section{The studied strains of the $B$. subtilis group}

For the research we used six strains from the $B$. subtilis group: three strains of $B$. subtilis species and three strains of $B$. pumilus species. All the bacilli were procured from Russian National Collection of Industrial Microorganisms (VKPM) and they are listed in Table 1.

Table 1. The strains of bacilli used in the research

$\begin{array}{ccc}\text { No of strain } & \text { Microbial species } & \text { Source } \\ 1 & \text { B. subtilis } & \text { VKPM: B-5449 } \\ 2 & \text { B. subtilis } & \text { VKPM: B-2896 } \\ 3 & \text { B. subtilis } & \text { VKPM: B-4828 } \\ 4 & \text { B. pumilus } & \text { VKPM: B-7886 } \\ 5 & \text { B. pumilus } & \text { VKPM: B-7917 } \\ 6 & \text { B. pumilus } & \text { VKPM: B-7919 }\end{array}$




\section{Nutrient media and culture conditions}

L-broth was used for the accumulation of biomass of bacilli. L-broth is composed of yeast extract (5 g/L), peptone (15 g/L), NaCl (5 g/L). Solid L-medium obtained by adding agar (15 g /L) to L-broth was used to antibiotic susceptibility assay.

Strains of $B$. subtilis group in L-broth were grown at $37^{\circ} \mathrm{C}$ in shaker-incubator «Innova $44 »(250 \mathrm{rpm})$ for $18-24 \mathrm{~h}$.

Plates with the strains of Bacillus spp. were incubated grown in a thermostat «Binder BD 115 » at $37^{\circ} \mathrm{C}$ for $18-24$ hours (Irkitova \& Grebenshchikova, 2018).

\section{Antibiotic susceptibility assay}

Antibiotic susceptibility of $B$. subtilis group strains was determined by classical disk diffusion test (Balouiri et al., 2016). Pour plate method was used for inoculation of incubated for 24 hours on L-broth bacilli on L-agar medium. Discs of different antibiotics (cephalexin, oleandomycin, enrofloxacin, benzylpenicillin, oxacillin and monomycin) were placed on the media in petri plates with the help of a sterile forceps. Plates with strains of bacilli without antibiotics were used as a control. After 24 hours of cultivation zones of inhibition were recorded in $\mathrm{mm}$ around the discs with the help of automatic color colony counter SCAN 1200. If the diameter of zone inhibition was $<10 \mathrm{~mm}$, the strain was regarded as resistance, 10-15 mm - as insensitive and 15-25 mm - as sensitive. Zones exceeding $25 \mathrm{~mm}$ indicate a high sensitivity of the microorganism to this antibiotic (MUK 4.2.1890-04, 2004).

\section{Statistical analysis}

The arithmetic average of the zones of growth inhibition of bacilli by antibiotics (M) and the standard deviation ( $\mathrm{m}$ ) were determined for the statistical analysis of the research results.

\section{Results}

For the studied strains of Bacillus spp., a different sensitivity to antibiotics was recorded (Table 2).

Table 2. Antibiotic sensitivity $(\mathrm{M} \pm \mathrm{m}, \mathrm{mm})$ of strains from the $B$. subtilis group

\begin{tabular}{lcccccc}
\hline Antibiotics & \multicolumn{7}{c}{ Strains } \\
& B. subtilis & B. subtilis & B. subtilis & B. pumilus & B. pumilus & B. pumilus \\
& B-5449 & B-2896 & B-4828 & B-7886 & B-7917 & B-7919 \\
Cephalexin & $47.8 \pm 1.9$ & $23.9 \pm 4.1$ & $36.8 \pm 0.7$ & $32.7 \pm 2.5$ & $36.7 \pm 3.8$ & $35.0 \pm 1.7$ \\
& $(+++)$ & $(++)$ & $(+++)$ & $(+++)$ & $(+++)$ & $(+++)$ \\
Oleandomycin & $18.3 \pm 1.2$ & 0 & $11.7 \pm 2.9$ & $16.7 \pm 0.6$ & $14.7 \pm 0.6$ & $16.3 \pm 1.2$ \\
& $(++)$ & $(-)$ & $(+)$ & $(++)$ & $(+)$ & $(++)$ \\
Enrofloxacin & $25.6 \pm 6.1$ & $32.8 \pm 2.5$ & $21.4 \pm 4.1$ & $27.3 \pm 0.6$ & $28.0 \pm 1.0$ & $27.0 \pm 1.0$ \\
Benzylpenicillin & $(+++)$ & $(+++)$ & $(++)$ & $(+++)$ & $(+++)$ & $(+++)$ \\
& $10.1 \pm 0.5$ & $5.4 \pm 1.3$ & $11.0 \pm 2.6$ & $13.3 \pm 0.6$ & $16.3 \pm 2.1$ & $13.7 \pm 1.2$ \\
Oxacillin & $(+)$ & $(-)$ & $(+)$ & $(+)$ & $(++)$ & $(+)$ \\
& 0 & $5.0 \pm 0.4$ & 0 & 0 & 0 & 0 \\
6. Monomycin & $(-)$ & $(-)$ & $(-)$ & $(-)$ & $(-)$ & $(-)$ \\
& $18.9 \pm 3.9$ & $12.6 \pm 2.3$ & $11.1 \pm 1.8$ & $14.3 \pm 0.6$ & $13.3 \pm 0.6$ & $13.7 \pm 0.6$ \\
& $(++)$ & $(+)$ & $(+)$ & $(+)$ & $(+)$ & $(+)$ \\
\hline
\end{tabular}

* «-»- resistance, «+» - insensitive, «++» - sensitive, «+++»- highly sensitive.

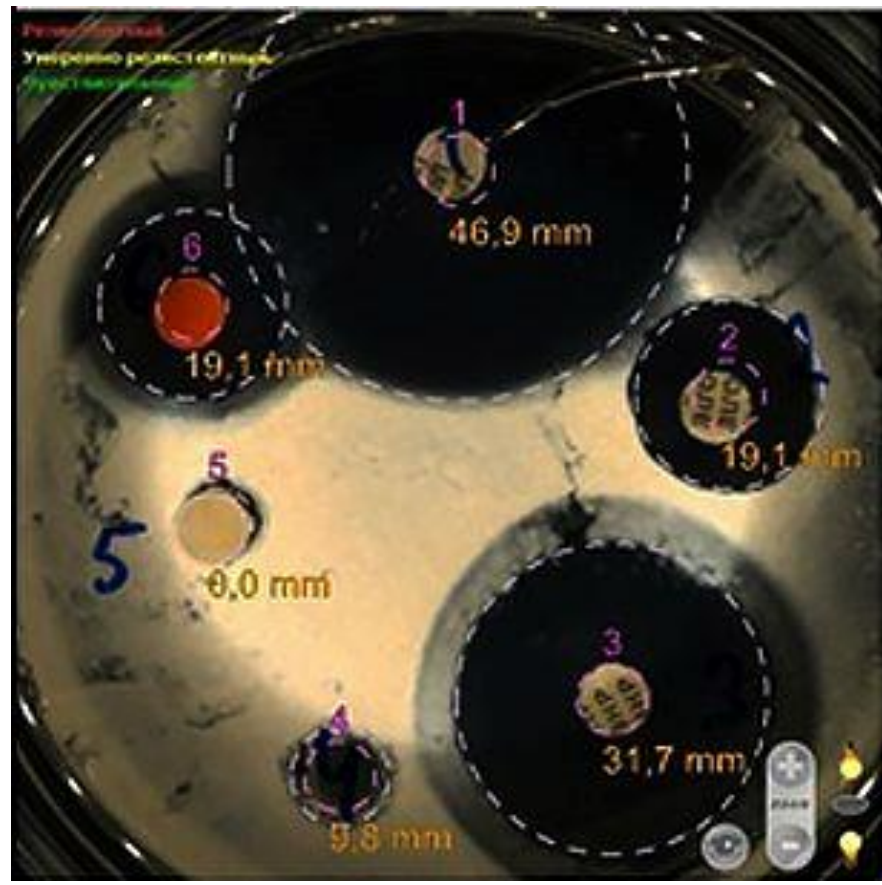

Fig. 1. The sensitivity of the $B$. subtilis B-5449 strain to the studied antibiotics. 
The sensitivity of $B$. pumilus bacteria to antibiotics was higher and more uniform within the species - the level of susceptibility to 3 of 6 antibiotics (cephalexin, enrofloxacin and oxacillin) was the same. For all strains of the $B$. subtilis species, the level of antibiotic sensitivity was uniform only to one of antimicrobial compounds (oxacillin).

The $B$. subtilis B-5449 strain was the least resistant to the studied antibiotics. This strain was the only one that showed sensitivity to $66.7 \%$ of antibiotics with an inhibition zone diameter more than $15 \mathrm{~mm}$ (Fig. 1).

Significant part ( $83.3 \%$ ) of the studied strains of bacilli showed a high sensitivity to cephalexin and enrofloxacin, while $100 \%$ of the strains were resistant to oxacillin, and the B. subtilis B-2896 strain alone showed resistant to $50 \%$ of the antibiotics used in this work.

\section{Discussion}

In this work, we used antibiotics from different classes to obtain the most complete picture of the sensitivity of bacteria from the $B$. subtilis group to antibacterial compounds. $\beta$-lactams (penicillins - benzylpenicillin and oxacillin, cephalosporins cephalexin), macrolides (oleandomycin), fluoroquinolones (enrofloxacin) and aminoglycosides (monomycin). Mechanisms of these antibiotics action are various: they can inhibit the synthesis of peptidoglycan, DNA and proteins, and also cause lysis of the microbial cell, i.e. act both bactericidal and bacteriostatic (Zakharochkina, 2013).

It is known that enrofloxacin, which has a wide spectrum of antibacterial action, as well as monomycin and oleandomycin, are effective against gram-positive aerobes (Selizarova, 2003; Zheldakova, 2004; Trouchon \& Lefebvre, 2016), which include all the studied strains. That is why the most part of the $B$. subtilis group strains showed sensitivity to these antibiotics.

Cephalosporins are more resistant to $\beta$-lactamases than penicillins (Bush \& Bradford, 2016). In our study, this was confirmed as high sensitivity to cephalexin in $83.3 \%$ of $B$. subtilis group strains.

Bacilli are often resistant to penicillins (Andrews \& Wise, 2002; Owusu-Kwarteng et al., 2017) and it is can be seen from the absolute resistance of all strains to oxacillin. It is known that benzylpenicillin is destroyed by bacterial penicillinase (Ismail \& Adeloju, 2010); therefore, the sensitivity of most of the studied strains, although small, to this antibiotic may indicate that they lack the necessary enzyme.

Since the strain $B$. subtilis B-2896 was the only one that was resistant to oleandomycin and benzylpenicillin, we can talk about the acquired antibiotic resistance of this bacterium to through horizontal gene transfer, or due to the occurrence of chromosomal DNA mutations.

A more variative level of susceptibility to antibiotics among bacteria of $B$. subtilis species may indicate their higher variability compared to strains from $B$. pumilus species. However, for a more detailed study of the differences between strains of the $B$. subtilis group in terms of antibiotic sensitivity, it is necessary to conduct a molecular genetics analysis in order to establish mechanisms of antibiotic resistance.

\section{Conclusion}

For all studied strains of the $B$. subtilis group, a high sensitivity to cephalexin (cephalosporins) and enrofloxacin (fluoroquinolones), as well as resistance to oxacillin (penicillins), which indicates the phylogenetic relationship of these bacilli, were noted. Differences in the level of sensitivity to other antibacterial compounds indicate the influence of environmental conditions in which each Bacillus strains lived. The $B$. subtilis B-5449 strain was the least resistant to the studied antibiotics, and the $B$. subtilis $\mathrm{B}-2896$ strain was the most resistant.

\section{References}

Alonso, A., Sanchez, P., Martinez, J.L. (2001). Environmental selection of antibiotic resistance genes. Environmental microbiology, 3, 1-9. doi:10.1046/j.1462-2920.2001.00161.x

Andrews, J.M., Wise, R. (2002). Susceptibility testing of Bacillus species. Journal of Antimicrobial Chemotherapy, 49(6), 10401042. doi: 10.1093/jac/dkf063

Balouiri, M., Sadiki, M., Ibnsouda, S.K. (2016). Methods for in vitro evaluating antimicrobial activity: A review. Journal of Pharmaceutical Analysis, 6(2), 71-79. doi: 10.1016/j.jpha.2015.11.005

Bush, K. (2009) The Importance of $\beta$-Lactamases to the Development of New $\beta$-Lactams. In: Mayers DL (ed) Antimicrobial drug resistance. Humana Press, New York, pp 135-144. doi 10.1007/978-1-59745-180-2_12.

Bush, K., Bradford, P.A. (2016). $\beta$-Lactams and $\beta$-Lactamase Inhibitors: An Overview. Cold Springs Harbor Perspectives in Medicine, 6(8), a025247. doi: 10.1101/cshperspect.a025247

Guidelines (MUK) 4.2.1890-04 (2004). Determination of the sensitivity of microorganisms to antibacterial drugs. Guidelines. Moscow: Federal Center for State Sanitary and Epidemiological Supervision of the Ministry of Health of Russia.

Irkitova, A.N., Grebenshchikova, A.V. (2018). Antimicrobial action of a bacterial consortium containing strains of the genus Bacillus. Ukrainian Journal of Ecology, 8(4), 444-449.

Ismail, F., Adeloju, S.B. (2010). Galvanostatic Entrapment of Penicillinase into Polytyramine Films and its Utilization for the Potentiometric Determination of Penicillin. Sensors, 10(4), 2851-2868. doi: 10.3390/s100402851

Li, X.Z., Nikaido, H. (2009). Efflux-mediated drug resistance in bacteria: an update. Drugs, 69(12), 1555-1623. doi:10.2165/11317030-000000000-00000

Martinez, J.L., Baquero, F. (2000). Mutation Frequencies and Antibiotic Resistance. Antimicrobial Agents and Chemotherapy, 44 (7), 1771-1777; doi: 10.1128/AAC.44.7.1771-1777. 
Martinez, J.L., Sanchez, M.B., Martinez-Solano, L.E., Hernandez, A.G., Garmendia, L., Fajardo, A.T., Alvarez-Ortega, C. (2009). Functional role of bacterial multidrug efflux pumps in microbial natural ecosystems. FEMS microbiology reviews, 33, $430-449$. doi:10.1111/j.1574-6976.2008.00157.x

Nikaido, H. (2009). Multidrug resistance in bacteria. Annual review of biochemistry, 78, $119-146$. doi:10.1146/annurev.biochem.78.082907.145923

Owusu-Kwarteng, J., Wuni, A., Akabanda, F., Tano-Debrah, K., Jespersen, L. (2017). Prevalence, virulence factor genes and antibiotic resistance of Bacillus cereus sensu lato isolated from dairy farms and traditional dairy products. BMC Microbiology, 14, 65. doi: 10.1186/s12866-017-0975-9

Selizarova, N.O. (2003). Antibiotics that disrupt the synthesis of macromolecules. Clinical Pharmacology and Drug Therapy Reviews, 1(1), 71-79.

Semenov, V.M., Zhyltsov, I.V., Dmitrachenko, T.I., Skvortsova, V.V., Zenkova, S.K., Vasilyeva, M.A. (2013). Beta-lactamase activity is the main cause of bacterial resistance to beta-lactam antibiotics. Clinical Infectology and Parasitology, 3(06), 52-65. Sidorenko, S.V., Tishkov, V.I. (2004). Molecular basis of antibiotic resistance. Advances in Biological Chemistry, 44, 263-306. Trouchon, T., Lefebvre, S. (2016). A Review of Enrofloxacin for Veterinary Use. Open Journal of Veterinary Medicine, 6, 40-58. doi: 10.4236/ojvm.2016.62006

Vinogradova, K.A., Bulgakova, V.G., Polin, A.N., Kozhevin, P.A. (2013). Microbial Antibiotic Resistance: Resistome, Its Volume, Diversity and Development. Antibiotics and Chemotherapy, 5-6, 38-48.

Zakharochkina, E.R. (2013). Vital and essential drugs: antibiotics. Remedium. Magazine on the Russian market of medicines and medical equipment, 6, 34-43.

Zheldakova, R.A. (2004). The mechanisms of biosynthesis of antibiotics and their effect on microorganism cells. Minsk: BSU, 111.

\section{Citation:}

Irkitova, A.N., Grebenshchikova, A.V., Dudnik, D.E. (2019). Antibiotic susceptibiity of bacteria from the Bacillus subtilis group. Ukrainian Journal of Ecology, 9(3), 363-366.

(cc) $\mathrm{EY}$ This work is licensed under a Creative Commons Attribution 4.0. License 